\title{
Computing Is a Profession
}

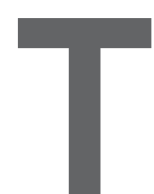

HE NOTION OF what constitutes a profession has been studied extensively through exploration of the attributes of the activities, roles, and community that lead to their rise, definition, and how they achieve importance and influence and society. ${ }^{1}$ Common among these attributes are a deep technical expertise, an essential, valued, societal contribution, and the need to adhere to high ethical and technical standards. Professions such as medicine, law, and accounting exemplify these attributes. Computing exhibits all of the attributes of a profession.

Deep Technical Expertise. Every day we witness and drive computing's rapid technical advance-new technologies, advancing sophistication, and outright new capabilities. The compounding of this continued and accelerating advance give rise to a deep technical expertise. $\mathrm{Al}$ gorithms and systems behavioral and internal complexity are peers to the greatest complexities humanity has known in biology, society, and the universe.

Societal Recognition. Computing's evident importance to society is deep and growing - sophisticated collection and information processing underpins decision-making, logistics, and optimization industry and commerce. Web, email, and messaging platforms are the information backbone of government and commerce. Social application platforms expand these roles from official to social, insinuating computing into the core of social fabric. A world without cheap, pervasive computing of extraordinary capability is if not inconceivable at least so distant as to be unrecognizable. Just as modern existence without the practice of medicine or law would be unimaginable.

Necessity for High Ethical and Technical Standards. The practice of comput- ing demands adherence to the highest technical and ethical standards, and failure has significant consequences at personal, corporate, national, and international scale. Computing applications reach into every corner. Appropriation, misuse, or just free flow of this information has demonstrably destroyed individual privacy, relationships, and careers (for example, Ashley Madison), grand corporate plans (for example, Sony), and radically changed international relations (for example, U.S. Govt OPM penetration, and Snowden releases).

With growing excitement for artifical intelligence, computing is being thrust into new societal roles (recommender, decider) and given autonomy to make decisions with life-changing human impact (personal assistant, sentencing guidelines, self-driving cars). While deep technical challenges abound, the ethical challenges, principles, and standards are even more daunting. Compared to Hanks' "rulebook" in Bridge of Spies, the underlying principles of a representative government, as embodied in the Constitution of the U.S., and one can only wonder if the issues are any less thorny.

Soyes, computing is a profession, and we should proudly embrace the responsibility. We should welcome, educate, and mentor new generations not just as "coders" and "hackers" or programmers, but as computing professionals.

Computing professionals have a responsibility to practice at the stateof-the-art, and maintain their knowledge at the forefront. In addition, professionals have an obligation to share clear understanding of the technology and its implications to nonprofessionals, and operate in accord with professional ethics. ${ }^{2}$ These are daunting goals for an individual, and so professional societies play a critical role in cultivating and supporting pro- fessionalism. What roles specifically?

First, a professional society should be a conservator and disseminator of deep technical knowledge and expertise: championing the advance of the field by leading technologists worldwide, documenting the state-of-the-art in technology and application, and accelerating the dissemination and availability of such knowledge to computing professionals.

Second, societies develop and advocate principles for ethical technical conduct that frame the role of computing professionals, and buttress them with the stature and role of the profession in society. Examples include the articulation of best practices, intellectual challenges for the field, ${ }^{3}$ as well as address societal questions that require deep technical perspective, such as the USACM joint release on the Internet of Things. ${ }^{4}$

An independent professional society must transcend any individual, organization, government, or cause. Necessarily so, as technical knowledge and professional ethics must inform professional conduct, and inevitably come into conflict with personal interest, corporate interest, government or national interest, or even overt coercion.

As the leading computing professional society, the ACM seeks to fill these roles for computing!

\section{Andrew A. Chien, E DITOR-IN-CHIE F}

Andrew A. Chien is the William Eckhardt Distinguished Service Professor in the CS Department at the University of Chicago, Director of the CERES Center for Unstoppable Computing, and a Senior Scientist at Argonne National Lab.

\footnotetext{
References

1. Abbott, A. The System of Professions: An Essay on the Division of Expert Labor. University of Chicago Press, 1988, ISBN-13: 978-0226000695

2. ACM Code of Ethics, (1992); https://www.acm.org/ about-acm/code-of-ethics

3. Denning, P.J. The Profession of IT. Columns in Commun. ACM, 2008-2017.

4SACM. Statement on Internet of Things Privacy and Security, 2017; https://www.acm.org/

Copyright held by author.
} 